\title{
Efeito do processamento UAT (Ultra Alta Temperatura) sobre as características físico-químicas do leite
}

\author{
Effect of UHT (Ultra High Temperature) processing on the physicochemical characteristics of milk
}

\author{
Ana Maria Centola Vidal MARTINS ${ }^{1}$, Oswaldo Durival ROSSI JUNIOR ${ }^{2 *}$, Bruna Maria SALOTTI ${ }^{2}$, \\ Karina Paes BÜRGER², Ana Ligia Lordello CORTEZ², Marita Vedovelli CARDOZO²
}

\begin{abstract}
Resumo
Com o objetivo de analisar as características físico-químicas do leite UAT durante sua industrialização e de comparar os resultados com a legislação vigente, foram analisadas 150 amostras, colhidas em seis etapas, em diferentes fases do processamento, sendo 60 de leite cru, 60 de leite pasteurizado e 30 de leite UAT. As amostras foram submetidas à determinação de acidez titulável, densidade, teor de gordura, extrato seco total (EST) e desengordurado (ESD), ponto crioscópico, pH, redutase, estabilidade ao álcool 68\% e à pesquisa das enzimas peroxidase e fosfatase alcalina. Os resultados indicaram que os valores médios do extrato seco total e do extrato desengordurado, bem como do índice crioscópico apresentaram-se, em algumas colheitas, inferiores aos estabelecidos pela legislação vigente, indicando possível aumento no teor de água do leite.
\end{abstract}

Palavras-chave: leite cru; leite pasteurizado; leite UAT; provas físico-químicas.

\begin{abstract}
With the aim of analyzing the physicochemical characteristics of UHT milk during its industrialization and comparing the results with the Brazilian legislation, 150 samples collected in six stages, in different processing phases, were analyzed, being 60 samples of raw milk, 60 of pasteurized milk and 30 of UHT milk. The samples were submitted to the analysis of Dornic acidity, density, fat content, total solids, solids-non-fat, freezing point, $\mathrm{pH}$, methylene blue reduction, stability to $68 \%$ alcohol and screening for peroxidase and alkaline phosphatase enzymes. The results indicated that the mean values of total solids and solids-non-fat and freezing point, were in some collections, lower than the limits established in the Brazilian legislation, demonstrating a possible increase in milk water content.

Keywords: raw milk; pasteurized milk; UHT milk; physicochemical characteristics.
\end{abstract}

\section{Introdução}

Dentre os alimentos de origem animal de maior consumo destaca-se o leite e, em particular, o leite tratado por ultra alta temperatura (leite UAT), tendo em vista a sua praticidade de conservação e uso e também seu longo período de vida comercial. No que diz respeito à sua qualidade, a duplicidade de tratamento térmico (pasteurização e processo UAT) aplicada ao produto, devido à má qualidade da matéria-prima, atua desfavoravelmente sobre as propriedades físico-químicas responsáveis pela manutenção do equilíbrio físico do leite (PRATA, 1998).

Uma elevada carga de microrganismos mesófilos, psicrotróficos e/ou termófilos no leite, através do seu desenvolvimento, degradam constituintes ou produzem substâncias capazes de alterar as propriedades físico-químicas, importantes na manutenção do produto. Matérias-primas de algum modo alteradas experimentarão, quando houver o processo por UAT ou subseqüente armazenamento e comercialização, alterações irreversíveis, modificando e comprometendo a qualidade do produto, ressaltando-se que grande parte das proteínas solú- veis é representada pelas albuminas e globulinas, de conhecida sensibilidade térmica (PRATA, 1998).

Antes do tratamento por Ultra Alta Temperatura (UAT), o leite cru deve passar por um tratamento térmico prévio. O processo mais adotado nesta fase é a pasteurização rápida (HTST - 73 a $75^{\circ} \mathrm{C} / 15$ segundos), como forma de eliminar as bactérias psicrotróficas e as enzimas termosensíveis por elas produzidas (BASTOS, 1999). Nesta fase deve-se avaliar a acidez, a densidade, a gordura e a crioscopia do leite, visando sua liberação para o tratamento por UAT (PRATA, 1998; SANDROW; ARVANITOYANNIS, 2000).

No tratamento por UAT o ponto mais importante é o binômio tempo/temperatura, que garante a obtenção de um processo de esterilização comercial. Temperaturas abaixo das estabelecidas são indesejáveis e acima podem causar problemas tecnológicos com alterações das proteínas, interferindo no sabor, geleificação, formação de sedimentos, bloqueio da transferência de calor nas superfícies dos trocadores de calor,

1 Centro Universitário de Rio Preto - UNIRP, São José do Rio Preto - SP, Brasil

2 Departamento de Medicina Veterinária Preventiva e Reprodução Animal, Faculdade de Ciências Agrárias e Veterinária, Universidade Estadual Paulista - UNESP, CEP 14884-900, Jaboticabal - SP, Brasil, E-mail: rossijr@fcav.unesp.br

${ }^{*}$ A quem a correspondência deve ser enviada 
perda do valor nutricional e escurecimento (BASTOS, 1999). $\mathrm{O}$ pH do leite diminui pela ação do tratamento térmico e esse decréscimo é provavelmente o fator individual mais importante que leva à coagulação pelo calor (FRANCO; LANDGRAF, 1996; PRATA, 1998).

Segundo o Regulamento Técnico de Identidade e Qualidade de Produtos Lácteos do Ministério da Agricultura, Pecuária e Abastecimento (BRASIL, 1997), o leite UAT deve atender as seguintes características sensoriais: aspecto líquido, cor branca, odor e sabor característicos, sem sabores nem odores estranhos e as seguintes características físico-químicas para o leite integral: no mínimo $3 \%$ de gordura, acidez entre 14 e $18{ }^{\circ} \mathrm{D}$, estabilidade ao álcool de $68 \%$ e, no mínimo, 8,2\% de desengordurado (ESD).

Tendo em vista o apresentado, idealizou-se o presente trabalho com o objetivo de trazer informações acerca das características físico-químicas do leite UAT ao longo da industrialização, bem como a comparação dos resultados obtidos com a legislação vigente.

\section{Material e métodos}

Foi analisado, quanto às características físico-químicas, um total de 150 amostras de $1 \mathrm{~L}$ de leite, colhidas a cada 2 meses, totalizando seis etapas (A a F), em diferentes fases do processamento de leite UAT, sendo divididas em 60 amostras de leite cru, 60 de leite pasteurizado e 30 de leite UAT. As amostras de leite cru foram colhidas do silo de armazenamento de leite $\mathrm{cru}$, as de leite pasteurizado do silo de armazenamento de leite pasteurizado e as de leite UAT tiveram colhidas as caixas logo após o processamento em uma indústria situada no Estado de São Paulo, submetida ao Serviço de Inspeção Federal e com capacidade de produção de 450.000 L de leite UAT por dia, sob o método de aquecimento direto (injeção de vapor no leite).

As características físico-químicas estudadas compreenderam a determinação da acidez titulável pelo método de Dornic, da densidade, do teor de gordura pelo método de Gerber, do extrato seco total e do extrato desengordurado, através do calculador de Ackerman, do índice crioscópico em lactocrioscópio eletrônico digital, do $\mathrm{pH}$ entre 20 e $22^{\circ} \mathrm{C}$ em peagâmetro, da estabilidade com emprego de solução alcoólica a $68 \%$, da prova da redutase empregando-se solução de azul de metileno (apenas para o leite cru) e da pesquisa das enzimas peroxidase utilizando-se solução alcoólica de guaiacol e fosfatase alcalina através do kit da Labtest Diagnostica S.A. (BRASIL, 1981).

As análises foram realizadas no Laboratório de Análise de Alimentos de Origem Animal e Água do Departamento de Medicina Veterinária Preventiva e Reprodução Animal da Faculdade de Ciências Agrárias e Veterinárias, Campus de Jaboticabal - UNESP.

\section{Resultados e discussão}

Na Tabela 1 estão apresentadas as médias aritméticas dos resultados das análises físico-químicas por colheita e tipo de leite. Os resultados demonstram que após o tratamento térmico aplicado ao leite ocorreram algumas alterações nos valores dos parâmetros, sendo que para a acidez titulável, pH e índice crioscópico as alterações foram para mais e para menos entre as colheitas. O teor de gordura diminuiu em todas elas em função da padronização (3\%) que o leite sofre antes da pasteurização. Diminuições ocorreram também nos valores da densidade, do EST e do ESD.

$\mathrm{Na}$ pesquisa das enzimas peroxidase e fosfatase alcalina verificaram-se resultados positivos no leite cru, negativos para a fosfatase no leite pasteurizado e negativos para ambas no leite UAT. Constata-se que tanto a pasteurização quanto o tratamento por UAT foram aplicados ao leite, respeitando o binômio tempo/ temperatura e confirmando a esterilização comercial, pois as enzimas presentes no leite cru estavam ausentes no leite UAT.

Como pode ser visto ainda na Tabela 1, o tempo de redução do azul de metileno na prova da redutase variou de 120 a 210 minutos.

A legislação brasileira estabelece padrões físico-químicos para o leite cru e para o leite pasteurizado tipo C, sendo, no mínimo, $3 \%$ de gordura, acidez entre 14 e $18^{\circ} \mathrm{D}$, densidade entre 1028 e 1034 g.L $\mathrm{L}^{-1}$, índice crioscópico máximo de $-0,530{ }^{\circ} \mathrm{H}$, no mínimo $11,5 \%$ de EST, no mínimo 8,4\% de ESD e redutase de, no mínimo, 90 minutos (apenas leite cru) (BRASIL, 1997). Pode-se notar, na Tabela 1, que as amostras de leite cru de todas as colheitas estavam de acordo com os parâmetros de gordura, acidez, densidade e redutase estabelecidos pela legislação. Porém, para o ESD apenas as amostras das colheitas A, B e F estavam de acordo com o exigido e, para o índice crioscópico, com exceção da colheita B, todas as outras estavam de acordo com o padrão estabelecido pela legislação.

No tocante às características físico-químicas do leite pasteurizado, estavam em desacordo com os padrões oficiais (BRASIL, 1997) para o índice crioscópico as amostras das colheitas A e B, e para o ESD as amostras das colheitas C, D, E e F.

Como demonstrado na Tabela 1, na colheita A as médias do $\mathrm{pH}$ verificado no leite cru $(5,6)$ e pasteurizado $(5,9)$ apresentaram valores abaixo do considerado normal para leite. Tal fato demonstrou-se curioso, pois teoricamente um leite com $\mathrm{pH}$ inferior a 6,1 nem deveria ser aceito pela indústria pelo fato de não suportar o tratamento térmico (estabilidade), podendo ocorrer a coagulação pelo calor.

Soares et al. (2003) verificaram que, das 169 amostras de leite cru analisadas, 19,1\% para acidez, 14,28\% para densidade, $8,5 \%$ para o EST e $16,4 \%$ para o ESD, estavam em desacordo com o estabelecido pela legislação. Tais resultados diferem dos encontrados no presente estudo, nos quais apenas os parâmetros crioscopia e ESD foram responsáveis por reprovação, 16 e 50\%, respectivamente. Carlos et al. (2004) analisaram 43 amostras de leite pasteurizado tipo $\mathrm{C}$ quanto às características físicoquímicas e verificaram que algumas amostras apresentavam-se em desacordo com o padrão estabelecido para o EST e ESD, assemelhando-se aos obtidos no presente estudo.

Como no presente estudo, Carvalho et al. (2004) verificaram que $100 \%$ de 30 amostras de leite cru analisadas apresentaram tempos de redutase superiores a 90 minutos, estando de acordo 
Martins et al.

Tabela 1. Média aritmética das características físico-químicas das amostras de leite cru, pasteurizado e UAT colhidas durante o processo de produção do leite UAT.

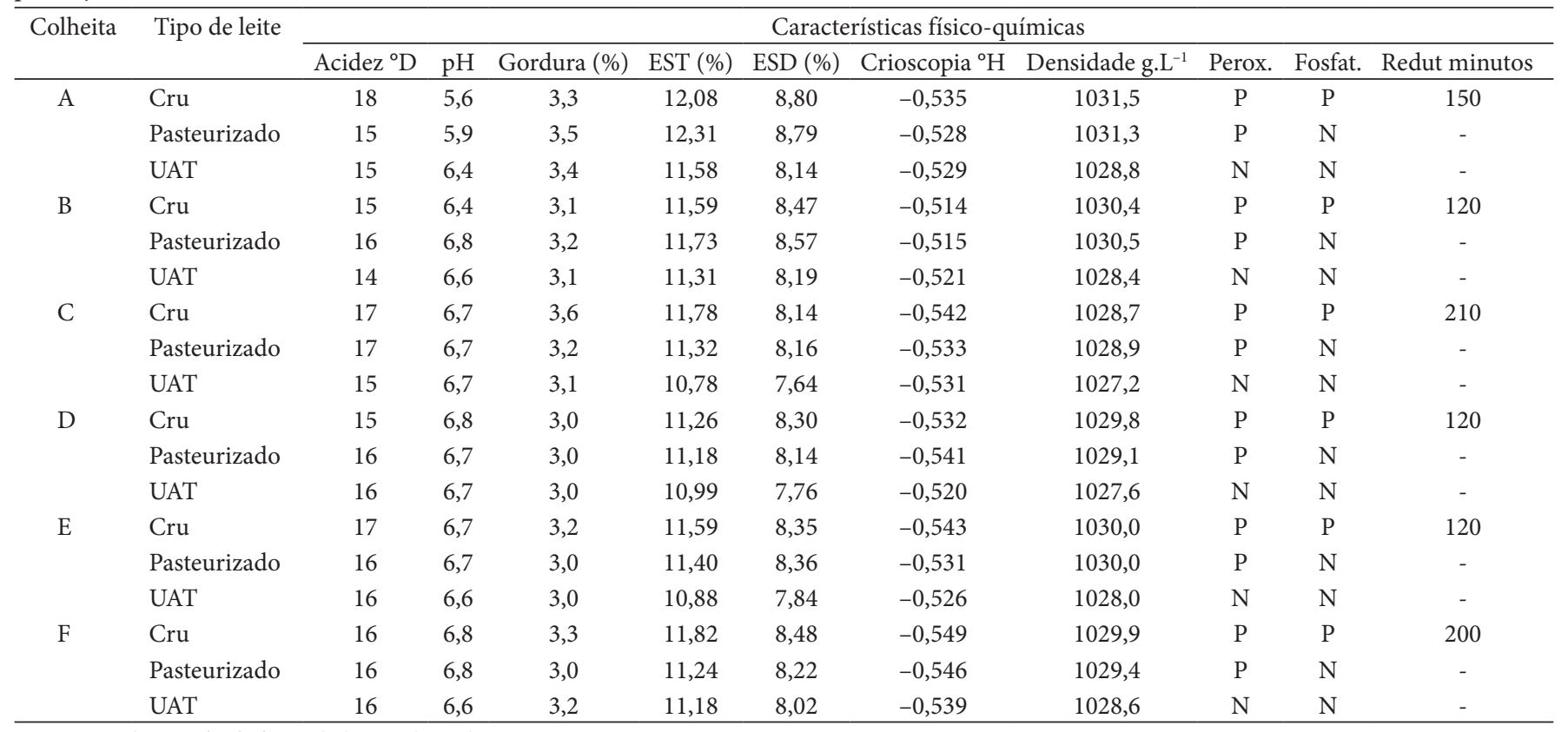

Perox: peroxidase; Fosfat: fosfatase alcalina; Redut: redutase; P: positiva; e N: negativa.

com o estabelecido pela legislação, que preconiza tempo de redução acima deste valor.

Souza et al. (2003) observaram que de 30 amostras analisadas de leite cru e pasteurizado, o EST foi o parâmetro que apresentou o maior percentual de amostras em desacordo com o padrão, totalizando $46,6 \%$ para o leite cru e $63,3 \%$ para o leite pasteurizado. No presente estudo, além do EST, o ESD também foi responsável por colocar 33 e $58 \%$ das amostras, respectivamente, em desacordo com a legislação.

Pinto et al. (2003), analisando 11 amostras de leite pasteurizado, verificaram que $28 \%$ delas estavam em desacordo com o padrão quanto ao teor de gordura, apesar do produto ser vendido como integral, além da reprovação de 8,33, 16,67 e 13,89\% nos requisitos densidade, EST e ESD, respectivamente. No presente trabalho todas as amostras analisadas foram aprovadas para os requisitos gordura e densidade, porém para os requisitos EST e ESD as amostras das colheitas C, D, E e F apresentaram-se abaixo do estabelecido (11,5 e 8,4\%, respectivamente).

Silva et al. (2003), avaliando a qualidade físico-química de 10 amostras de leite pasteurizado tipo $C$, verificaram que a acidez variou de 16 a $20^{\circ} \mathrm{D}$, resultados semelhantes aos encontrados no presente trabalho. Os autores citados observaram também que $70 \%$ das amostras estavam em desacordo com a legislação, no que se refere aos valores de densidade, teor de gordura e EST, e 50\% em relação ao ESD.

Tinôco et al. (2002) analisaram 30 amostras de leite pasteurizado quanto às características físico-químicas e verificaram que a fosfatase alcalina, como no presente estudo, foi negativa para todas as amostras, mostrando assim que foi atendida a temperatura mínima utilizada na pasteurização. Porém, os autores encontraram resultados diferentes do presente estudo quando pesquisaram a enzima peroxidase, pois encontraram três amostras negativas, indicando assim superaquecimento das mesmas e, conseqüentemente, uma possível diminuição no valor nutritivo.

Cardoso e Araújo (2003) analisaram 163 amostras de leite pasteurizado quanto ao padrão físico-químico estabelecido pela legislação vigente, e verificaram que o parâmetro responsável pelo maior número de condenação foi o índice crioscópico, assemelhando-se assim ao presente estudo, no qual foi verificado em quatro (66\%) colheitas um índice inferior ao estabelecido (no mínimo $-0,530^{\circ} \mathrm{H}$ ). Segundo os autores citados, o índice crioscópico é uma das características mais constantes do leite, variando muito pouco em função da raça, clima e outro fatores, significando que alterações indicam adição de água ao leite.

Segundo a legislação, o leite UAT deve apresentar no mínimo $3 \%$ de gordura, acidez entre 14 e $18^{\circ} \mathrm{D}$, no mínimo $8,2 \%$ de ESD e estabilidade ao álcool 68\% (BRASIL, 1997).

Todas as amostras testadas se mostraram estáveis na prova do álcool 68\%. Como apresentado na Tabela 1, o leite UAT de todas as colheitas obedeceu aos parâmetros gordura e acidez, porém com relação ao ESD nenhuma das amostras atendeu ao estabelecido. Como na maioria das colheitas os resultados de ESD em desacordo estão relacionados com uma crioscopia também variada, eles indicam um aumento no teor de água no leite, que pode estar relacionado a falhas no processamento, pois logo após o tratamento por UAT é retirada a água que condensou durante a injeção de vapor quente ao leite.

Silva (2001) e Bizari (2002) analisaram amostras de leite cru (matéria-prima) e UAT e verificaram que todas estavam de acordo com o estabelecido pela legislação brasileira. Tais resultados diferenciam-se dos encontrados no presente estu- 
do, cujos valores verificados foram inferiores para densidade, EST e ESD.

Rabelo (2003) analisou 90 amostras de leite UAT e verificou que, com exceção de uma amostra que estava em desacordo com o padrão para crioscopia, todas as demais estavam de acordo com o estabelecido pela legislação vigente.

Em trabalho semelhante, Barros et al. (2003) avaliaram os parâmetros físico-químicos de 30 amostras de leite UAT e verificaram que, para a gordura e para a crioscopia, todas as amostras estavam de acordo com os padrões da legislação brasileira. Porém, os autores verificaram alguns valores de acidez, densidade, EST e ESD em desacordo com o padrão estabelecido pela legislação vigente.

\section{Conclusões}

Os resultados permitiram verificar que os valores médios do extrato seco total, do extrato desengordurado e do índice crioscópico apresentaram-se, em algumas colheitas, inferiores aos estabelecidos pela legislação vigente, indicando possível aumento no teor de água no leite UAT, evidenciando assim falha no processamento.

\section{Agradecimentos}

Agradecemos à FAPESP pela bolsa de estudo e pelo auxílio pesquisa concedidos para a realização do presente estudo.

\section{Referências bibliográficas}

BASTOS, M. S. R. Leite longa vida UHT: Aspectos do processamento e identificação dos pontos críticos de controle. Revista Higiene Alimentar, São Paulo, v. 13, n. 66/67, p. 32-36, 1999.

BIZARI, P. A. Eficiência da contagem microscópica na avaliação da qualidade pregressa da matéria-prima utilizada no processamento de leite $\mathrm{UAT}^{\star}$. ( ${ }^{\star}$ ultra alta temperatura). Jaboticabal, 2002, 53 p. Dissertação (Mestre em Medicina Veterinária Preventiva), Faculdade de Ciências Agrárias e Veterinárias, Universidade Estadual Paulista (UNESP).

BRASIL. Ministério da Agricultura e do Abastecimento. Secretaria Nacional de Defesa Agropecuária. Laboratório Nacional de Referência Animal - LANARA. Métodos Analíticos para o Controle de Produtos de Origem Animal e seus Ingredientes - Métodos Físico-Químicos. Diário Oficial da União, Brasília, 1981, p. XIV1-22.

. Ministério da Saúde. Portaria n. 451, 19 de setembro de 1997. Regulamentos técnicos. Princípios gerais para o estabelecimento de critérios e padrões microbiológicos para alimentos. Diário Oficial da União, Brasília, 22 set. 1997. Seção 1, p. 21005-210112.

CARDOSO, L.; ARAÚJO, W. M. C. Parâmetros de qualidade em leites comercializados no Distrito Federal, no período 1997-2001. Revista Higiene Alimentar, São Paulo, v. 17, n. 114/115, p. 34-40, 2003.

CARLOS, L. A. et al. Avalação físico-química, microbiológica e de resíduos de penicilina, em leite tipo " $\mathrm{C}$ ” comercializado no município de Campos dos Goytacazes, RJ. Revista Higiene Alimentar, São Paulo, v. 18, n. 123, p. 57-61, 2004.

CARVALHO, M. G. X. et al. Análise microbiológica do leite in natura e pasteurizado tipo " $\mathrm{C}$ " proveniente de uma mini-usina da cidade de Patos, Paraíba. Revista Higiene Alimentar, São Paulo, v. 18, n. 123 , p. 62-66, 2004.

FRANCO, B. D. G. M.; LANDGRAF, M. Microbiologia dos Alimentos. São Paulo: Atheneu, 1996. p. 155-164.

PINTO, A. T. et al. Padrão de qualidade do leite pasteurizado integral produzido no Rio Grande do Sul. In: CONGRESSO LATINO- AMERICANO DE HIGIENISTAS DE ALIMENTOS, 1. CONGRESSO BRASILEIRO DE HIGIENISTAS DE ALIMENTOS, 7, 2003, Belo Horizonte. Anais... Belo Horizonte - MG: Sociedade Brasileira de Higienistas de Alimentos, 2003. p. 152-153.

PRATA, L. F. Leite UHT: solução ou problema? Uma análise da situação. Revista Higiene Alimentar, São Paulo, v. 12, n. 54, p. 10-15, 1998.

RABELO, R. N. Avaliação retroativa da qualidade microbiológica da matéria-prima utilizada em leites UAT comerciais. Jaboticabal, 2003. 75 p. Dissertação (Mestrado em Medicina Veterinária Preventiva), Faculdade de Ciências Agrárias e Veterinárias Universidade Estadual Paulista (UNESP).

SANDROW, D. K.; ARVANITOYANNIS, I. S. Implementation of hazard analysis critical control point (HACCP) to the dairy industry: current status and perspectives. Food Reviews International, London, v. 16, n. 1, p. 77-111, 2000.

SILVA, E. O. T. R. E. Leite longa vida integral: avaliação de alguns parâmetros de qualidade dos leites cru e processado. São Paulo, 2001. 122 p. Tese (Doutorado em Epidemiologia Experimental e Aplicada às Zoonoses) - Faculdade de Medicina Veterinária e Zootecnia, Universidade de São Paulo (USP).

SILVA, S. R. N. C. et al. Qualidade físico-química do leite pasteurizado tipo $\mathrm{C}$ em um estabelecimento no estado do Maranhão. In: CONGRESSO LATINO-AMERICANO DE HIGIENISTAS DE ALIMENTOS, 1. CONGRESSO BRASILEIRO DE HIGIENISTAS DE Alimentos, 7, 2003, Belo Horizonte. Anais... Belo Horizonte - MG: Sociedade Brasileira de Higienistas de Alimentos, 2003. p. 194.

SOARES, F. M.; FONSECA, L. M.; NEPOMUCENO JÚNIOR, F. Características físico-químicas e rendimento de leite "in natura" recebido em um laticínio no interior do estado do Rio de Janeiro. In: CONGRESSO LATINO-AMERICANO DE HIGIENISTAS DE ALIMENTOS. CONGRESSO BRASILEIRO DE HIGIENISTAS DE ALIMENTOS. 2003, Belo Horizonte. Anais... Belo Horizonte - MG: Sociedade Brasileira de Higienistas de Alimentos, 2003. p.199.

SOUZA, S. M. B. et al. Características físico-químicas do leite "in natura' e pasteurizado na mini-usina de beneficiamento de leite na cidade de Patos - PB. In: CONGRESSO LATINO-AMERICANO DE HIGIENISTAS DE ALIMENTOS. CONGRESSO BRASILEIRO DE HIGIENISTAS DE ALIMENTOS. 2003, Belo Horizonte. Anais... Belo Horizonte - MG: Sociedade Brasileira de Higienistas de Alimentos, 2003. 251 p.

TINÔCO, A. L. A. et al. Análises das condições físico-químicas do leite oferecido ao comércio em Viçosa - MG. Revista Higiene Alimentar, São Paulo, v. 16, n. 98, p. 101-106. 2002. 